\title{
DYNAMIC NEUROMUSCULAR STABILIZATION LEBIH MENINGKATKAN KESEIMBANGAN DINAMIS DARIPADA PERCEPTUAL MOTOR PROGRAM PADA ANAK DOWN SYNDROME USIA 7-15 TAHUN DI YAYASAN PRADNYAGAMA DENPASAR
}

\author{
Merinda Ulfa ${ }^{1}$, Ketut Tirtayasa ${ }^{2}$, Wahyuddin ${ }^{3}$, Susy Purnawati ${ }^{4}$, Luh Putu Ratna Sundari ${ }^{5}$, \\ Muhammad Irfan ${ }^{6}$ \\ ${ }^{1}$ Program Magister Fisiologi Keolahragaan Fakultas Kedokteran, Universitas Udayana, Denpasar \\ 2,4,5 Bagian Ilmu Faal, Fakultas Kedokteran, Universitas Udayana, Denpasar \\ ${ }^{3}$ Fakultas Fisioterapi, Universitas Esa Unggul, Jakarta \\ ${ }^{6}$ Program Studi Fisioterapi Universitas ‘Aisyiyah Yogyakarta
}

\begin{abstract}
ABSTRAK
Pendahuluan: Gangguan keseimbangan dinamis sering ditemukan pada anak down syndrome yang menyebabkan kesulitan mempertahankan postur tubuh ketika gangguan datang. Permasalahan perkembangan motorik selanjutnya akan timbul jika dibiarkan. Tujuan: Untuk mengetahui intervensi fisioterapi yang dapat meningkatkan keseimbangan dinamis pada anak down syndrome usia 7-15 tahun. Metode: Penelitian bersifat true eksperimental dengan pre test dan post test group design. Penelitian memakai 24 subjek dalam 2 kelompok, Kelompok $1(\mathrm{n}=12)$ diberikan dynamic neuromuscular stabilization sedangkan Kelompok $2(\mathrm{n}=12)$ diberikan perceptual motor program. Latihan dilakukan tiga kali seminggu selama enam minggu. Alat ukur keseimbangan dinamis adalah sixteen balance test. Hasil: Uji paired sample t-test pada Kelompok 1 menunjukkan perbedaan bermakna dengan nilai $(\mathrm{p}<0,001)$ pada rerata sebelum intervensi 48,5 $\pm 5,428$ dan sesudah intervensi 72,75 $\pm 4,413$. Uji paired sample t-test pada Kelompok 2 menunjukkan perbedaan bermakna dengan nilai ( $\mathrm{p}<0,001$ ) pada rerata sebelum intervensi 48,5 $\pm 5,3$ dan sesudah intervensi 69,42 $\pm 4,379$. Uji beda antara Kelompok 1 dan 2 menggunakan independent sample t-test menunjukkan perbedaan bermakna $(\mathrm{p}<0,001)$. Simpulan: Dynamic neuromuscular stabilization lebih baik daripada perceptual motor program dalam meningkatkan keseimbangan dinamis pada anak down syndrome usia 7-15 tahun di Yayasan Pradnyagama Denpasar.
\end{abstract}

Kata kunci : Dynamic neuromuscular stabilization, perceptual motor program, keseimbangan dinamis, down syndrome. 


\title{
DYNAMIC NEUROMUSCULAR STABILIZATION MORE INCREASING DYNAMIC BALANCE THAN PERCEPTUAL MOTOR PROGRAM AMONG CHILDREN WITH DOWN SYNDROME AGES 7-15 YEARS IN PRADNYAGAMA DENPASAR FOUNDATION
}

\begin{abstract}
Background: Disorder of dynamic balance is often found in children with Down syndrome which causes difficulty in maintaining posture against impending disorders. If this is left it will certainly cause problems of further motor development. Purpose: To prove the physiotherapy intervention that can improve dynamic balance among children with down syndrome 7-15 years. Methods: The research is true experimental with pre-test and post-test group design. This study used 24 subjects in 2 groups, group $1(\mathrm{n}=11)$ given dynamic neuromuscular stabilization on while group $2(\mathrm{n}=11)$ given perceptual motor program. Divided randomly into 2 groups that is group 1 dynamic neuromuscular stabilization and group 2 perceptual motor program. The exercise is held 3 times a week in 6 weeks. Measurements of this dynamic balance are using sixteen balance tests. Result: The paired sample t-test statistical test in group 1 showed a significant difference with value $(\mathrm{p}<0.001)$ on mean before intervention $48.5 \pm 5.428$ and after intervention $72.75 \pm 4.413$. The paired sample t-test statistical test in group 2 showed a significant difference with value $(\mathrm{p}<0.001)$ on mean before intervention $48.5 \pm 5.3$ and after intervention $69.42 \pm 4.379$. Different test between group 1 and 2 using independent sample t-test showed a significant difference with value $(\mathrm{p}<0.001)$. Conclusion: The conclusions are dynamic neuromuscular stabilization is better than perceptual motor program in improving dynamic balance among children with down syndrome 7-15 years at Pradnyagama Foundation Denpasar.
\end{abstract}

Keywords: Dynamic neuromuscular stabilization, perceptual motor program, dynamic balance, down syndrome. 


\section{PENDAHULUAN}

Down syndrome merupakan bentuk genetik dan gangguan perkembangan intelektual yang paling sering diidentifikasi dengan kelainan kromosom 21. Kromosom tersebut terbentuk akibat kegagalan sepasang kromosom ketika saling memisahkan diri pada saat terjadi pembelahan. Sebagian besar anak dengan down syndrome telah mengalami penurunan kekuatan dan tonus otot (hypotone), mobilitas sendi berlebihan atau hypermobile pada persendian dan kekurangan neurodevelopmental, motorik, dan kognitif. ${ }^{1}$

Permasalahan yang terjadi pada anak down syndrome salah satunya gangguan keseimbangan yang menghambat perkembangan kognitif, persepsi gerakan dan proprioseptif. Dalam hal ini sangat membatasi dan mempengaruhi kualitas hidup down syndrome yang menyebabkan terhambatnya banyak aktivitas hidup seharihari, memberikan keterbatasan dalam melakukan pekerjaan fisik dan peningkatan ketergantungan pada orang lain. ${ }^{2}$

Dalam mempertahankan keseimbangan bukanlah kebutuhan utama namun sangat diperlukan manusia untuk melakukan tindakan yang dibutuhkan pada saat bergerak. Hampir semua anak down syndrome yang banyak terjadi sudah dibuktikan mengalami gangguan keseimbangan. Keseimbangan yang tidak baik yang terjadi pada awal perkembangan akan mengakibatkan keterlambatan dalam perkembangan kemampuan motorik. Permasalahan perkembangan motorik selanjutnya akan timbul jika dibiarkan. ${ }^{3}$

Tindakan fisioterapi yang bisa diberikan untuk meningkatkan keseimbangan dinamis pada anak down syndrome salah satunya adalah dynamic neuromuscular stabilization yang bertujuan untuk mengaktifkan integrated spinal stabilizing system dan mengembalikan regulasi intra abdominal pressure yang ideal untuk mengoptimalkan efisiensi gerakan dan untuk mencegah beban sendi yang berlebihan. Latihan yang digunakan adalah posisi perkembangan bayi usia 3-12 bulan pada tingkatan kontrol motorik subkortikal pada central nervous system, di mana pada tingkat ini terjadi proses kematangan stabilitas postural. ${ }^{4,5}$

Pemberian intervensi selanjutnya dalam mengatasi permasalahan keseimbangan dinamis adalah dengan perceptual motor program yang bertujuan untuk melatih sistem saraf sehingga anak mengembangkan kemampuan mengingat pola pergerakan, urutan suara dan tampilan serta nuansa benda. Pendekatan intervensi dini untuk memfasilitasi pengembangan motorik pada bayi dan anak-anak dengan down syndrome sebagai bukti adanya hubungan yang signifikan dengan perceptual motor memiliki persepsi gerakan dan mempengaruhi keseimbangan dalam jangka panjang pada anak down syndrome. ${ }^{6}$

\section{METODE PENELITIAN}

\section{A. Rancangan Penelitian}

Penelitian bersifat true experimental dengan pre test and post test group design.

\section{B. Tempat dan Waktu Penelitian}

Penelitian dilaksanakan di Yayasan Pradnyagama Denpasar. Pelaksanaan waktu penelitian di bulan Januari-Februari 2018. Intervensi diberikan tiga kali seminggu selama enam minggu. Kelompok 1 dan kelompok 2 diberikan tiga kali seminggu selama enam minggu dapat sebagai edukasi kepada keluarga untuk dilakukan setiap hari di rumah.

\section{Populasi dan Sampel}

Populasi penelitian yaitu semua anak down syndrome di Yayasan Pradnyagama Denpasar yang berusia 7-15 tahun yang telah memenuhi kriteria inklusi dan ekslusi. 


\section{Teknik Pengambilan Sampel}

Jumlah sampel yang masuk kriteria inklusi sebanyak 24 sampel dengan teknik simple random sampling. Pembagian kelompok dilakukan secara acak sederhana dengan metode random alokasi dari subjek yang telah terpilih pada setiap kelompok terdiri dari 12 anak down syndrome. Kelompok 1 mendapatkan perlakuan dynamic neuromuscular stabilization sedangkan kelompok 2 perceptual motor program.

\section{E. Prosedur Penelitian}

1. Melakukan perizinan pada institusi tempat penelitian.

2. Peneliti memberikan edukasi kepada orang tua dan sampel mengenai manfaat, tujuan dan bagaimana penelitian ini dilakukan.

3. Setelah dilakukan pemeriksaan, sampel dibagi menjadi dua bagian yaitu kelompok pertama dan kelompok kedua.

4. Sebelum dan sesudah dilaksanakan intervensi, kedua kelompok dilakukan pemeriksaan keseimbangan dinamis menggunakan sixteen balance test.

5. Evaluasi dan melakukan perbandingan hasil sebelum dan sesudah intervensi kedua kelompok perlakuan setelah enam minggu penelitian.

6. Kemudian dilakukan uji beda dan semua data yang telah didapatkan diolah dengan statistik.

7. Mempersiapkan alat ukur yang memiliki ketelitian yang diakui secara ilmiah.

\section{F. Analisis Data}

Menganalisis data yang diperoleh menggunakan beberapa uji statistik :

1. Menganalisis karakteristik sampel jenis kelamin, umur dan nilai indeks massa tubuh dari tiap sampel menggunakan statistik deskriptif.
2. Uji normalitas data dengan shapiro wilk test pada kedua kelompok hasilnya adalah data berdistribusi normal $(\mathrm{p}>0,05)$ dan selanjutnya dilakukan uji parametrik.

3. Uji homogenitas dengan Levene's test. Hasil yang didapatkan bahwa sebaran data bersifat homogen $(\mathrm{p}>0,05)$.

4. Uji hipotesis 1 menggunakan paired sample t-test pada Kelompok dynamic neuromuscular stabilization karena data berdistribusi normal.

5. Uji hipotesis 2 pada Kelompok perceptual motor program digunakan paired samples t-test karena data berdistribusi normal.

6. Uji hipotesis III menggunakan independent sample t-test pada kelompok 1 dan kelompok 2 karena data berdistribusi normal.

\section{HASIL PENELITIAN}

\section{Deskripsi Karakteristik Subjek}

Subjek penelitian adalah anak down syndrome yang terbagi menjadi dua kelompok yang terdiri dari 12 anak pada masing-masing kelompok.

Deskripsi data berupa karakteristik subjek penelitian yaitu jenis kelamin, umur dan nilai IMT.

Tabel 1. Karakteristik Subjek Penelitian

\begin{tabular}{|c|c|c|c|c|c|}
\hline \multirow{2}{*}{$\begin{array}{l}\text { Karakteristi } \\
\mathrm{k}\end{array}$} & \multirow{2}{*}{ Kategori } & \multicolumn{2}{|c|}{$\begin{array}{c}\text { Frekuens } \\
\text { i }\end{array}$} & \multicolumn{2}{|c|}{$\begin{array}{c}\text { Persentase } \\
(\%)\end{array}$} \\
\hline & & $\begin{array}{l}\mathrm{K} 1 \\
\mathrm{p} 1\end{array}$ & $\begin{array}{l}\mathrm{K} 1 \\
\mathrm{p} 2\end{array}$ & $\begin{array}{c}\text { Klp } \\
1 \\
\end{array}$ & $\begin{array}{c}\text { Klp } \\
2\end{array}$ \\
\hline \multirow{3}{*}{$\begin{array}{l}\text { Jenis } \\
\text { Kelamin }\end{array}$} & Laki-laki & 3 & 7 & $25 \%$ & $58 \%$ \\
\hline & $\begin{array}{l}\text { Perempua } \\
\mathrm{n}\end{array}$ & 9 & 5 & $75 \%$ & $42 \%$ \\
\hline & Total & 12 & 12 & $\begin{array}{c}100 \\
\% \\
\end{array}$ & $\begin{array}{c}100 \\
\%\end{array}$ \\
\hline \multirow{3}{*}{ Umur (th) } & $7-10$ & 8 & 10 & $67 \%$ & $83 \%$ \\
\hline & $11-15$ & 4 & 2 & $33 \%$ & $17 \%$ \\
\hline & Total & 12 & 12 & $\begin{array}{c}100 \\
\%\end{array}$ & $\begin{array}{c}100 \\
\%\end{array}$ \\
\hline $\begin{array}{c}\text { IMT } \\
\left(\mathrm{kg} / \mathrm{m}^{2}\right)\end{array}$ & Normal & 12 & 12 & $\begin{array}{c}100 \\
\%\end{array}$ & $\begin{array}{c}100 \\
\%\end{array}$ \\
\hline
\end{tabular}




\begin{tabular}{ccccc} 
Total & 12 & 12 & $\begin{array}{c}100 \\
\%\end{array}$ & $\begin{array}{c}100 \\
\%\end{array}$ \\
\hline
\end{tabular}

Pada Tabel 1 menunjukkan bahwa pada Kelompok 1 memiliki jumlah laki-laki 3 anak (25\%) dan perempuan 9 anak (75\%), sedangkan di Kelompok 2 memiliki jumlah laki-laki 7 anak (58\%) dan perempuan 5 anak (42\%). Distribusi umur pada Kelompok 1 menunjukkan jumlah sampel yang memiliki rentang usia 7-10 tahun berjumlah 8 anak (67\%) dan rentang usia 11-15 tahun terdiri dari 4 anak (33\%). Pada Kelompok 2 distribusi umur dengan rentang usia 7-10 tahun terdiri dari 10 anak (83\%) dan rentang usia 11-15 tahun terdiri dari 2 anak (17\%). Distribusi IMT pada Kelompok 1 dan Kelompok 2 menunjukkan bahwa nilai IMT memiliki kategori normal.

\section{Uji Normalitas dan Homogenitas Data}

Tabel 2. Uji Normalitas dan Homogenitas dari Probabilitas (p) dari Rerata Nilai Keseimbangan Dinamis Kedua Kelompok

\begin{tabular}{|c|c|c|c|}
\hline \multirow{3}{*}{$\begin{array}{c}\text { Keseimbangan } \\
\text { Dinamis }\end{array}$} & \multicolumn{2}{|c|}{ Uji Normalitas $^{\mathrm{a}}$} & Uji \\
\hline & $\begin{array}{c}\text { Kelompok } \\
1 \\
\end{array}$ & $\begin{array}{c}\text { Kelompok } \\
2 \\
\end{array}$ & Nilai $\mathrm{p}$ \\
\hline & Nilai p & Nilai p & \\
\hline $\begin{array}{l}\text { Sebelum } \\
\text { Intervensi }\end{array}$ & 0,516 & 0,927 & 0,200 \\
\hline $\begin{array}{l}\text { Sesudah } \\
\text { Intervensi }\end{array}$ & 0,566 & 0,316 & 0,200 \\
\hline
\end{tabular}

Keterangan:

$\mathrm{a}=$ Shapiro Wilk Test

$\mathrm{b}=$ Levene's Test

Hasil uji normalitas dengan data berdistribusi normal pada Kelompok 1 dan 2 sebelum dan sesudah perlakuan menunjukkan nilai probabilitas $(\mathrm{p}>0,05)$. Hasil uji homogenitas dengan data homogen pada kedua kelompok sebelum dan sesudah perlakuan didapatkan nilai $(\mathrm{p}>0,05)$.

\section{Perbedaan Keseimbangan Dinamis Sebelum dan Sesudah Pemberian Dynamic Neuromuscular Stabilization dan Perceptual Motor Program}

Tabel 3. Uji Beda Peningkatan

Keseimbangan Dinamis (skor SBT) pada

Kelompok 1 dan Kelompok 2 Sebelum dan Sesudah Perlakuan

\begin{tabular}{cccc}
\hline Kelompok & $\begin{array}{c}\text { Pre test } \\
\text { Rerata } \pm \text { SB }\end{array}$ & $\begin{array}{c}\text { Post test } \\
\text { Rerata } \pm \text { SB }\end{array}$ & $\begin{array}{c}\text { Nilai } \\
p^{*}\end{array}$ \\
\hline 1 & $19,3 \pm 3,49$ & $32,916 \pm 2,906$ & 0,001 \\
2 & $20,0 \pm 3,302$ & $31,25 \pm 3,018$ & 0,001 \\
\hline Nilai & 0,636 & 0,018 & - \\
$p^{* *}$ & & & \\
\hline
\end{tabular}

Keterangan :

$p^{*}=$ Diuji dengan paired sample t-test $p^{* *}=$ Diuji dengan independent t-test

Skor rerata peningkatan keseimbangan dinamis antara sebelum perlakuan 19,3 $\pm 3,49$ dan sesudah perlakuan $32,916 \pm 2,906$ pada Kelompok 1. Kelompok 2 mempunyai rerata skor peningkatan keseimbangan dinamis antara sebelum perlakuan sebesar 20,0 $\pm 3,302$ dan sesudah perlakuan 31,25 $\pm 3,018$. Paired sample t-test didapatkan hasil yang sama pada ke dua kelompok, maka ada beda secara bermakna rerata peningkatan keseimbangan dinamis sebelum dan sesudah perlakuan.

Hasil analisis beda rerata peningkatan keseimbangan dinamis pada ke dua Kelompok dengan menggunakan independent sample t-test. Hal ini menunjukkan bahwa dynamic neuromuscular stabilization lebih baik dibanding dengan perceptual motor program dalam meningkatkan keseimbangan dinamis pada anak down syndrome. 


\section{PEMBAHASAN}

\section{Pemberian Dynamic Neuromuscular Stabilization Meningkatkan Keseimbangan Dinamis}

Program pelatihan stabilitas inti mengarahkan untuk aktivitas yang mengantisipasi penyesuaian postural dan mengurangi gangguan awal dari center of gravity. Reaksi postural awal dari sistem neuromuskuler adalah kontraksi dari core stability muscle. Aktivasi yang proporsional pada otot-otot stabilisator sendi selama melakukan gerakan sangat penting karena aktivasi yang tidak proporsional dapat mengakibatkan gangguan dalam tubuh yang bisa mempengaruhi postur dan gerakan yang dihasilkan oleh ektremitas. ${ }^{4,7}$

\section{Pemberian Perceptual Motor Program Meningkatkan Keseimbangan Dinamis}

Perceptual motor menggabungkan antara kemampuan persepsi dan aksi gerak yang dilakukan anak sehingga anak dapat mempelajari untuk mengontrol berat tubuh dan membangkitkan kontrol postural. Perceptual motor dapat meningkatkan kemampuan anak dengan menitikberatkan fokus perhatian anak pada gerak terhadap lingkungannya. Adanya adaptasi dan pemilihan strategi yang sesuai dengan lingkungan (kontak sentuhan) akan didukung oleh persepsi atau aksi akan menambah pemahaman pada kontrol postural. ${ }^{8,9,10}$

\section{Efektivitas Dynamic Neuromuscular Stabilization dibandingkan Perceptual Motor Program}

Berdasarkan nilai rerata pada kedua kelompok perlakuan tersebut, kelompok 1 mengalami peningkatan keseimbangan dinamis yang lebih besar yaitu $33,33 \%$ dibandingkan dengan kelompok 2 yang hanya mempunyai nilai $30,14 \%$.

Hasil penelitian tersebut sesuai dengan teori dan tindakan intervensi yang dilakukan oleh Kobesova dan Kolar tentang prinsip dynamic neuromuscular stabilization yang mengajarkan untuk mengintegrasikan pola pernapasan dan stabilitas yang optimal pada aktivitas sehari-hari dan performa olahraga. Stabilitas yang optimal yang dicapai melalui pelatihan dynamic neuromuscular stabilization memungkinkan respons motorik yang efektif, efisien dan tepat waktu akibat adanya gangguan dari sistem sensoris (proprioseptif dan vestibular) dalam mempertahankan keseimbangan pada gerakan dinamis. Stabilitas yang optimal juga dapat mencegah dan mengembalikan pergeseran yang terjadi pada COG selama melakukan gerakan dinamis. Sistem sensoris dan motoris berkontribusi dalam mempertahankan keseimbangan. Stimulasi rangsangan dari sistem sensoris diperlukan untuk mendeteksi kondisi yang tidak stabil dan sistem motorik memiliki kontribusi yang sangat penting dalam memulai respons yang tepat waktu untuk mengantisipasi gangguan. ${ }^{4,11}$

Hasil penelitian, teori dan tindakan intervensi tersebut diperkuat lagi bahwa otot transversus abdominalis dan multifidus yang termasuk dalam core stability muscle untuk menstabilkan otot ketika otot yang digunakan berhubungan dengan sistem saraf pusat akan memberikan umpan balik ke posisi sendi dengan baik. ${ }^{12}$

Dari hasil penelitian tersebut, penulis menyimpulkan bahwa pendekatan dynamic neuromuscular stabilization lebih baik dibandingkan dengan perceptual motor program karena terjadi proses stimulasi rangsangan yang dimulai dari tingkat dasar untuk memperoleh postural kontrol yang bagus sehingga kemampuan anak down syndrome akan terus menerus terstimulasi untuk mengintegrasikan pola pernapasan dan 
stabilitas postural. Peningkatan keseimbangan dinamis yang terjadi pada anak down syndrome akan memberikan dampak yang baik pada kualitas hidupnya. ${ }^{13}$

\section{SIMPULAN}

1. Pemberian dynamic neuromuscular stabilization dapat meningkatkan keseimbangan dinamis pada anak down syndrome usia 7-15 tahun di Yayasan Pradnyagama Denpasar.

2. Pemberian perceptual motor program dapat meningkatkan keseimbangan dinamis pada anak down syndrome usia 7-15 tahun di Yayasan Pradnyagama Denpasar.

3. Pemberian dynamic neuromuscular stabilization lebih meningkatkan keseimbangan dinamis pada anak down syndrome usia 7-15 tahun di Yayasan Pradnyagama Denpasar dibandingkan perceptual motor program.

\section{DAFTAR PUSTAKA}

1. Masgutova, S., Sadowska, L., Kowalewka, J., Masgutov, D., Akhmatova, N., Filipowski, H. 2015. Use of a Neurosensorimotor Reflex Integration Program to Improve Reflex Patterns of Children with Down Syndrome. Journal of Neurology and Neuroscience. Vol. 6, No. 4 : 59.

2. Davidson, G.C \& Neale J.M. 2006. Psikologi Abnormal. Jakarta: PT. Raja Grafindo Persada.

3. Cronin, G.W., Rine, R.M. 2010. Pediatric Vestibular Disorders Recognition, Evaluation and Treatment. Vestibular Disorders Association. Available from: www.vestibular.org

4. Frank, C., Kobesova, A. and Kolar, P. 2013. Dynamic Neuromuscular Stabilization \& Sports Rehabilization.
The International Journal of Sports Physical Therapy. Vol. 8.

5. Huston, M. and Ward, A. 2015. Oxford Textbook of Musculoskeletal Medicine. Second Edition. United State: Oxford University Press.

6. Babul, N.V., Kerns, K., Zhou, E., Kapur, A., Shiffrar, M. 2006. Perceptual motor deficits in children with Down syndrome: Implications for intervention. Down Syndrome Research Foundation. Victoria: University of Victoria.

7. Ahmadi, R., Hasan, D., dan Hosin, B.A. 2012. The effect of 6 weeks core stabilization training program on the balance in mentally retarded students. International Journal of Sport Studies. Vol. 2, No. 10 : 496-501.

8. Sajedi, F. 2014. The effect of Perceptual Motor Training on Motor Skills of Preschool Children. Iranian Rehabilitation Journal. Vol. 12, No. 19 : 14-17.

9. Ryalls, A.R., Manning, P.J., Sutherland, W.H.F., Walker, R.J., Williams, S.M., De Jong, S.A., \& Berry, E.A. 2016. The Combination of Perceptual Motor Program and Neurodevelopmental Treatment was Better than the Combination Kinesiotapping and Neurodevelopmental Treatment in Increase Sitting Ability in Cerebral Palsy. Sport and Fitness Journal. Vol. 12, No. 19.

10. Atilgan, O.E. 2012. Relationship Between Perceptual Motor Skill and Postural Balance in Nine Years Old Boys. Educational Research and Review. Vol. 7, No. 24.

11. Kobesova, A. and Kolar, P. 2013. Developmental Kinesiology: Three Levels of Motor Control in The Assessment and Treatment of The Motor System. Journal of Bodywork \& Movement Therapies. Vol. 20. 
12. Fredericson, M. and Moore, T. 2005. Muscular Balance, Core Stability, and Injury Prevention for Middle and Long Distance Runners. Physical Medicine Rehabilition Clinic of North America. Vol. 16 : 669-689.

13. Costa, P.D., Wahyuni, N., Purnawati, S. Dinata, I.M.K. 2016. Pelatihan Hatha Yoga Modifikasi dapat Meningkatkan Keseimbangan Dinamis pada Lansia di Denpasar Timur. Majalah Ilmiah Fisioterapi Indonesia. Vol.1, No.1:1-11. 